\title{
The Ethics of Organizations: A Longitudinal Study of the U.S. Working Population
}

\author{
Muel Kaptein
}

\begin{tabular}{|l|l|}
\hline \multicolumn{2}{|l|}{ ERIM REPORT SERIES RESEARCH IN MANAGEMENT } \\
\hline ERIM Report Series reference number & ERS-2009-018-ORG \\
\hline Publication & April 2009 \\
\hline Number of pages & 44 \\
\hline Persistent paper URL & http://hdl.handle.net/1765/15405 \\
\hline Email address corresponding author & mkaptein@rsm.nl \\
\hline Address & Erasmus Research Institute of Management (ERIM) \\
& RSM Erasmus University / Erasmus School of Economics \\
& Erasmus Universiteit Rotterdam \\
& P.O.Box 1738 \\
& 3000 DR Rotterdam, The Netherlands \\
& Phone: + 31 10 408 1182 \\
& Fax: + 31 10 408 9640 \\
& Email: info@erim.eur.nl \\
& Internet: $\quad$ www.erim.eur.nl \\
\hline
\end{tabular}

Bibliographic data and classifications of all the ERIM reports are also available on the ERIM website: www.erim.eur.nl 


\section{ERASMUS RESEARCH INSTITUTE OF MANAGEMENT}

\section{REPORT SERIES}

\section{RESEARCH IN MANAGEMENT}

\begin{tabular}{|c|c|}
\hline \multicolumn{2}{|c|}{ ABSTRACT AND KEYWORDS } \\
\hline Abstract & $\begin{array}{l}\text { The ethics of organizations has received much attention in recent years. This raises the question } \\
\text { whether the ethics of organizations has also improved. In 1999, } 2004 \text { and 2008, a survey was } \\
\text { conducted of 12,196 U.S. managers and employees. The results show that the ethical culture of } \\
\text { organizations only improved in the period between } 1999 \text { and 2004. Unethical behavior and its } \\
\text { consequences, however, declined between } 2004 \text { and 2008, while the scope of ethics programs } \\
\text { expanded in that period. The paper concludes with a discussion of the implications of these } \\
\text { findings for further research and practice. }\end{array}$ \\
\hline Free Keywords & $\begin{array}{l}\text { ethical culture, ethics program, unethical behavior, ethical reputation, ethics management, } \\
\text { virtue theory, stakeholder theory }\end{array}$ \\
\hline Availability & $\begin{array}{l}\text { The ERIM Report Series is distributed through the following platforms: } \\
\text { Academic Repository at Erasmus University (DEAR), DEAR ERIM Series Portal } \\
\text { Social Science Research Network (SSRN), SSRN ERIM Series Webpage } \\
\text { Research Papers in Economics (REPEC), REPEC ERIM Series Webpage }\end{array}$ \\
\hline Classifications & $\begin{array}{l}\text { The electronic versions of the papers in the ERIM report Series contain bibliographic metadata } \\
\text { by the following classification systems: } \\
\text { Library of Congress Classification, (LCC) LCC Webpage } \\
\text { Journal of Economic Literature, (JEL), JEL Webpage } \\
\text { ACM Computing Classification System CCS Webpage } \\
\text { Inspec Classification scheme (ICS), ICS Webpage }\end{array}$ \\
\hline
\end{tabular}


THE ETHICS OF ORGANIZATIONS:

\title{
A LONGITUDINAL STUDY OF THE U.S. WORKING POPULATION
}

\author{
Muel Kaptein \\ Department of Business-Society Management \\ Rotterdam School of Management, Erasmus University \\ Room T07-04 \\ P.O. Box 1738 \\ 3000 DR Rotterdam \\ The Netherlands \\ Tel.: +31 104082823 \\ E-mail: $\underline{\text { mkaptein@ @rsm.nl }}$ \\ Website: muelkaptein.com
}

Muel Kaptein, $\mathrm{PhD}$, is Professor of Business Ethics and Integrity Management at the Department of Business-Society Management at RSM, Erasmus University. His research interests include the management of ethics, the measurement of ethics, and the ethics of management. He has published papers in journals like Academy of Management Review, Business \& Society, Journal of Business Ethics, Journal of Management, Journal of Management Studies, Journal of Organizational Behavior, and Organization Studies. He is author of the books Ethics Management: Auditing and developing the ethical content of organizations (Springer, 1998), The Balanced Company: A corporate integrity approach (Oxford University Press, 2002), The Six Principles of Managing with Integrity: A practical guide (Articulate Press, 2005) and The Living Code: Embedding ethics into the corporate DNA (Greenleaf, 2008). Muel is also director of KPMG Integrity, which he co-founded in the Netherlands in 1996. For more information, visit the website: muelkaptein@com. 
THE ETHICS OF ORGANIZATIONS:

\title{
A LONGITUDINAL STUDY OF THE U.S. WORKING POPULATION ${ }^{1}$
}

\begin{abstract}
The ethics of organizations has received much attention in recent years. This raises the question whether the ethics of organizations has also improved. In 1999, 2004 and 2008, a survey was conducted of 12,196 U.S. managers and employees. The results show that the ethical culture of organizations only improved in the period between 1999 and 2004. Unethical behavior and its consequences, however, declined between 2004 and 2008, while the scope of ethics programs expanded in that period. The paper concludes with a discussion of the implications of these findings for further research and practice.
\end{abstract}

Key Words: Ethical culture, Ethics program, Unethical behavior, Ethical reputation, Ethics management, Virtue theory, Stakeholder theory 
The ethics of organizations has received much attention in recent years. New or revised laws and regulations have been enacted to improve the ethics of organizations, such as the 2002 Sarbanes-Oxley Act which was amended in 2004, the revised U.S. Federal Sentencing Guidelines for Organizations of 2004, and the new rules NYSE and NASDAQ introduced in the wake of the Sarbanes-Oxley Act. The U.S. Securities and Exchange Commission and U.S. Department of Justice have also increased their enforcement of the Foreign Corrupt Practices Act, which was introduced in 1977 and revised in 1997.

But awareness and concern about the ethics of organizations have increased also beyond the legal domain. For example, ethical and sustainable investing in the U.S. increased from $\$ 639$ billion in 1995 to $\$ 2,159$ billion in 1999 and from $\$ 2,290$ billion in 2005 to $\$ 2,711$ billion in 2007 (Social Investment Forum, 2007). Job seekers and consumers also give greater consideration to the ethics of organizations (Harrison, Newholm, and Shaw, 2005). For example, ethical consumerism in the U.K. tripled between 1999 and 2006 (The Co-operative bank, 2007) and 57\% of U.S. consumers currently say that their purchase decision could be influenced by whether or not a product supports a worthy cause (Nielsen, 2008). The number of international nongovernmental organizations that scrutinize the ethics of organizations has increased worldwide from 30,000 in 2000 to over 60,000 in 2007 (Union of International Associations, 2007). And the ethics of organizations has also gained a more prominent place in the curriculum of business schools: the percentage of international business schools that require students to take a course in business ethics has increased from $34 \%$ in 2001 to $63 \%$ in 2007 (Aspen Institute, 2007).

The question is whether the ethics of organizations has also improved as a result of these developments. On the one hand, the focus on the ethics of organizations has 
been prompted by scandals, such as the major bookkeeping scams at the beginning of the $21^{\text {th }}$ century and the more recent credit crisis, which suggests a weakening in the ethics of organizations. On the other hand, the widespread adoption of ethics programs suggests an improvement in organizational ethics. For example, $86 \%$ of the Fortune Global 200 companies had a code in 2007, compared to 49\% in 1999 (KPMG, 2008).

In this paper, the findings are reported of a longitudinal study of the ethics of U.S. organizations. The ethics of organizations is operationalized not only as the frequency of unethical behavior and the scope of ethics programs, but also as the ethical culture and the (potential) consequences of unethical behavior. One approach to examining these elements is to measure and analyze the perceptions of managers and employees. ${ }^{2}$ In this study, the 'KPMG Ethics \& Integrity Thermometer' was used to measure the perceptions of the U.S. working population at three different points in time: in 1999, before the major bookkeeping scandals were exposed, in 2004, after the bookkeeping frauds became public and new rules and regulations were promulgated in response to these incidents, and in 2008, when the first signs of the credit crisis emerged. The total number of respondents was 12,196. Before the findings are reported, the model and method will be discussed.

\section{A MODEL FOR MEASURING THE ETHICS OF ORGANIZATIONS}

To measure the ethics of organizations, we first have to distinguish the elements it is composed of. A model for measuring the ethics of organizations can be structured along the lines of three general business ethics theories. 
The three most frequently cited business ethics theories are virtue ethics, deontological ethics, and consequential ethics (Kaptein and Wempe, 2002). Virtue ethics, the intellectual roots of which can be traced back to Plato and Aristotle, focuses on the intentions, characteristics, qualities, attitudes, and disposition of agents. Deontological or duty-based ethics, such as Kantian ethics, focuses on the actions and behavior of agents. Consequential, or teleological ethics, such as utilitarianism which was developed by Mill and Bentham, focuses on the effects and results of the actions of agents. Virtue ethics focuses on who agents are, deontological ethics on what agents do, and consequential ethics on the impact of what agents do. An agent can be an individual, group and collective entity, such as an organization.

To measure the ethics of organizations, we can focus on the intentions of the organization, its conduct and effects. The intentions of an organization are located in the way in which the organization promotes ethical behavior and prevents unethical behavior. This study employed the Corporate Ethical Virtues Model developed by Kaptein (1998, 2008a). This is a model that distinguishes between a range of organizational virtues and lends itself to measuring the relevant intentions of an organization. To identify the organizational virtues with reference to which unethical behavior can be explained and prevented, Kaptein (2008a) analyzed multiple cases of unethical behavior Eight virtues were distinguished: (1) clarity, defined as the extent to which ethical expectations, such as values, norms and rules, are concrete, comprehensive and understandable to managers and employees; (2) congruency of management, defined as the extent to which the board and middle management behave in accordance with ethical expectations; (3) congruency of supervisors, defined as the extent to which local management behave in accordance with ethical expectations; (4) feasibility, defined as the extent to which the organization makes sufficient time, 
budgets, equipment, information and authority available to enable management and employees to fulfill their responsibilities; (5) supportability, defined as the extent to which the organization stimulates identification with, involvement in and commitment to ethical expectations among management and employees; (6) transparency, defined as the extent to which ethical and unethical behavior and its consequences are visible to those managers and employees who can act upon it; (7) discussability, defined as the extent to which ethical issues, such as ethical dilemmas and alleged unethical behavior, can be discussed internally by managers and employees; and (8) sanctionability, defined as the extent to which managers and employees believe that unethical behavior will be punished and ethical behavior will be rewarded, as well as the extent to which the organization learns from unethical behavior. Measurement of the perceptions of managers and employees regarding the existence of these virtues in their organization unravels the ethical culture of an organization. According to this approach, the stronger the presence of these virtues the more ethical the organization is.

Next to the informal intentions, an organization also has formal intentions which are labeled as the ethics program of an organization (Berenbeim, 1992; Ferrell, Thorne LeClair, and Ferrell, 1998; Treviño and Weaver, 2003). An ethics program consists of the measures, policies and instruments an organization adopts to promote ethical behavior and to deter unethical behavior. ${ }^{3}$ The ethical culture forms part of the soft controls of an organization and the ethics program forms part of the hard controls of an organization. Frequently cited and widely advocated components of an ethics program, which are also included in this study, are: (1) a code of ethics, (2) an ethics officer or ethics office, also called compliance office(r), ombudsperson or ethics committee, (3) ethics training and other types of information and communications, (4) a dedicated telephone system, usually called ethics hotline or ethics helpline, (5) policies to hold 
management and employees accountable for unethical behavior, (6) policies on investigating allegations of unethical behavior, (7) policies that create incentives and rewards for ethical behavior, (8) internal monitoring systems and ethics audits, and (9) pre-employment screenings of the ethics of applicants (cf., Treviño and Weaver, 2003; Kaptein, 2009). The ethical quality of an organization is directly related to the comprehensiveness and effective implementation of its ethics program. According to the Federal Sentencing Guidelines for Organizations, for example, the adoption of an effective ethics program demonstrates that an organization is "committed" and "capable" of preventing, detecting and responding to unethical behavior. The Guidelines also assert that organizations whose ethics programs are more effective will receive a lower penalty in the event of a legal violation than those whose programs are less effective.

Next to the informal intentions (ethical culture) and formal intentions (ethics program), behavior itself can be the object of measurement. The ethics of an organization is then based on, for example, the frequency of unethical behavior and the seriousness of ethical transgressions. Unethical behavior in and of organizations is commonly defined as behavior that violates generally accepted moral norms of behavior (Jones, 1991; Treviño, Weaver, and Reynolds, 2006). Ethical behavior implies adherence to these moral norms whereas unethical behavior implies the violation of these moral norms. Examples of commonly considered types of unethical behavior are 'corruption', 'fraud', 'stealing' and 'sexual harassment' (Crane and Matten, 2007).

Finally, the ethics of an organization can be derived from measuring the impact of the behavior of an organization, its managers and employees. The well-known stakeholder model, originally developed by Freeman (1984) and further developed by, for example, Donaldson and Preston (1995), Mitchell, Agle and Wood (1997), and 
Jones and Wicks (1999), is useful for framing this dimension of an organization's ethics. ${ }^{4}$ Stakeholders, such as shareholders, employees and customers, are those individuals and organizations who have an interest in the organization and who depend on the organization. Shareholders and other suppliers of financial capital, for example, primarily seek to achieve a good return on their investment, while the primary desire of customers is good quality products and services. From this perspective, the ethics of an organization can be deduced from the extent to which the legitimate interests of stakeholders are realized. The impact of (un)ethical behavior on the (direct) interests of the organization (which coincides but can also conflict with the interests of one or more stakeholder) can also be determined. Organizational interests include high levels of productivity, efficiency, market-share, reputation, and profit.

Figure 1 depicts the elements of the ethics of an organization as discussed above. Intentions, behavior and effects are related to each other: intentions influence behavior and behavior has effects. However, other factors may also influence behavior and its effects (see, for example, Baucus and Near (1991), Greenberg (2002), Jones, (1991) and Treviño (1986)). ${ }^{5}$ For the purpose of this study, we will focus on the elements as depicted in Figure 1. 


\section{FIGURE 1}

\section{A Model for Measuring the Ethics of Organizations}

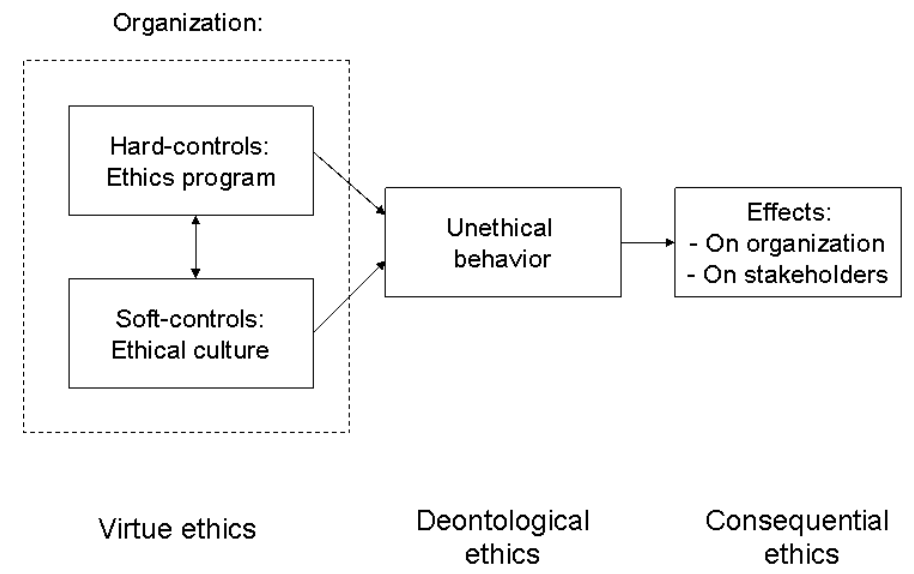

METHOD

\section{Sample}

Data was collected from the U.S. working population at three different points in time. KPMG, the employer of the author, commissioned one of the largest private panel database firms in the world, National Family Opinion (NFO) to compile a representative sample of U.S. adults working for organizations that employ at least 200 people in one of following eleven industries: Financial Services; Energy \& Chemicals; Real Estate \& Construction; Electronics, Software \& Services; Automotive; Aerospace \& Defense; Consumer Markets; Pharmaceuticals \& Life Sciences; Media \& Communications; Healthcare; and Government \& Public Sector. The privately registered respondents to this blind survey received a nominal financial reward from NFO for their participation. The first measurement took place between October 15 and November 15 in 1999, the second between November 2004 and March 2005, and the third between July and 
September 2008. The first measurement yielded 2,390, the second 4,056, and the third 5,065 completed questionnaires. Table 1 shows the demographic characteristics of all 12,196 respondents.

TABLE 1

\section{Demographics}

\section{Gender}

Men

Women

\section{Organization size}

200 - 999 employees

$1,000-2,999$

employees

$3,000-4,999$

employees

$5,000-9,999$

employees

$\geq 10,000$ employees

\section{Hierarchical position}

Individual contributor

Supervisor

Mid-Level manager

Senior manager / junior

executive

Senior executive /

officer / director

Individual contributor

Other

\section{Job tenure}

$<1$ year

$1-2$ years

$3-5$ years

$6-9$ years

$\geq 10$ years
$15.6 \%$

$61.6 \%$

$12.6 \%$

$7.0 \%$

$50.06 \%$

$49.94 \%$

$22.5 \%$

$12.4 \%$

$9.7 \%$

$39.8 \%$

$11.7 \%$

$3.5 \%$

$2.7 \%$

$61.6 \%$

$7.9 \%$

$10.3 \%$

$18.1 \%$

$16.6 \%$

$48.0 \%$

\section{Job function}

Sales / marketing

Operations / service

$10.6 \%$

Manufacturing /

$13.4 \%$

production

Research / development /

engineering

Purchasing / procurement $\quad 1.4 \%$

Technology

$8.9 \%$

Training / education

$3.8 \%$

Quality / safety /

environmental

$3.1 \%$

Clerical / support

$8.3 \%$

General management /

administration

Finance / accounting

$7.7 \%$

Legal / compliance

$5.2 \%$

$1.0 \%$

Internal audit / risk

management

$0.7 \%$

Public / media relations $\quad 0.6 \%$

Government / regulatory

affairs

$3.4 \%$

Other

$12.4 \%$

\section{Work location}

Corporate / organizational headquarters

General business / field

location

Very small / remote unit

$12.4 \%$

Age

$<35$ years $\quad 16.0 \%$

35 - 54 years $\quad 61.9 \%$

$\geq 55$ years 


\section{Scales}

Ethics programs. The construct of ethics programs was operationalized as the awareness of respondents about the existence of the nine, as presented above, different components of an ethics program in their organization. A response scale from " $0=$ not at all", "1 = informally", "2 = formally", "3 = unsure / no opinion", and "4 = not applicable" was used for each component. Because this study defines ethics programs as formal control systems, options 1, 3 and 4 were recoded to 0 (non-existent) and option 2 to 1 (existent). The scope of an ethics program was determined by the number of different components that are present in an organization (cf., Treviño, 2005; Weaver, Treviño, \& Cochran, 1999). Unfortunately, the complete set of questions about an ethics program was not included in the first measurement and some were also reformulated in the two subsequent measurements. The results obtained in 1999 are therefore incomplete and cannot be compared to the research results of 2004 and 2008.

Ethical culture. To measure the ethical culture of an organization, the virtue ethics model as discussed above was employed. ${ }^{6}$ For each of the eight dimensions, a five-point Likert type scale ranging from " $1=$ strongly disagree" to " $5=$ strongly agree" was used to measure different items. Reliabilities (Cronbach's alphas) of all dimensions were above the required minimum of 0.70 , as suggested by Nunally (1978). Due to the fact that the scale was slightly refined between 1999 and 2004, dummy scores substituted the questions that were not included in the first measurement. ${ }^{7}$

Unethical behavior. At the time of our first measurement only one scale was available for unethical behavior. However, this scale of 17 items, which was developed by Newstrom and Ruch (1975) and used by others (Akaah, 1996; Treviño, Butterfield, 
and McCabe, 1998; Jackson and Artola, 1997; Zey-Ferrell and Ferrell, 1982), is limited. As Newstrom and Ruch themselves stated, their scale only focuses on "managerial ethics and especially 'intraorganizational cheating' ... excluding ... major crimes and other social issues that typically arise at higher organizational levels or between organizations" (1975: 30). To expand the scope of unethical behaviors, a new list consisting of 22 items was developed. This list was based on the items collected by Kaptein (1998). Fortunately, in 2004 and 2008 a standardized scale as developed by Kaptein (2008b) could be used. This scale was developed in eight phases using a range of samples and resulted in a list composed of 37 items of unethical behavior. Each item is related primarily to one of five categories of stakeholders: financiers (10 items), customers (8 items), employees (5 items), suppliers ( 7 items), and society ( 7 items). Following Treviño, Butterfield and McCabe (1998), observed behavior was measured instead of self-reported behavior in order to reduce problems of social desirability bias. A time frame of twelve months was selected and each question reads: "In the past 12 months, I have personally seen or have first-hand knowledge of employees or managers in my work group...". A frequency scale consisting of five choices was used: 1 (never), 2 (rarely), 3 (sometimes), 4 (often), and 5 ((almost) always).

Effects. At the time the studies were conducted, no scale was available to measure the perceived effects of unethical behavior. Therefore, a new set of questions was developed. For stakeholders, the same five clusters as distinguished in the model for unethical behavior were used. The question read: "I believe the following stakeholders have favorable views about the ethics and integrity of my organization" and was measured using a five-point Likert-type scale ranging from " 1 = strongly disagree" to " $5=$ strongly agree" for each stakeholder. ${ }^{8}$ For the organization, the same response scale was used. The question was "If discovered, the violation(s) I observed 
could potentially result in..." Respondents were asked to indicate consequences ranging from "significant loss of public trust", "significant legal fines or sanctions", "significant loss of new or existing customers", and "significant loss of employee morale or productivity". This paper presents only the consequences measured in 2004 and 2008 as a different scale for unethical behavior was used in 1999.

\section{RESULTS}

In the following section the results are discussed, starting with the existence of ethics programs in U.S. organizations.

\section{Ethics programs}

Table 1 shows the extent to which nine different components of ethics programs were embedded in 2004 and 2008. 
TABLE 2

Components of Ethics Programs in 2004 and $2008^{9}$

\begin{tabular}{|c|c|c|c|}
\hline & & 2004 & 2008 \\
\hline 1 & $\begin{array}{l}\text { Code of ethics that articulates the values } \\
\text { and standards of the organization }\end{array}$ & $77.26 \%$ & $81.62 \%$ \\
\hline 2 & $\begin{array}{l}\text { Communication and training to employees } \\
\text { on code of conduct }\end{array}$ & $68.98 \%$ & $76.34 \%$ \\
\hline 3 & $\begin{array}{l}\text { Policies to hold employees accountable for } \\
\text { code of conduct violations }\end{array}$ & $64.63 \%$ & $70.98 \%$ \\
\hline 4 & $\begin{array}{l}\text { Policies to investigate and take corrective } \\
\text { action if misconduct is alleged }\end{array}$ & $64.85 \%$ & $70.64 \%$ \\
\hline 5 & $\begin{array}{l}\text { Background investigations on prospective } \\
\text { employees }\end{array}$ & $59.95 \%$ & $66.52 \%$ \\
\hline 6 & Confidential and anonymous ethics hotline & $47.69 \%$ & $57.44 \%$ \\
\hline 7 & Senior-level ethics or compliance officer & $51.25 \%$ & $56.15 \%$ \\
\hline 8 & $\begin{array}{l}\text { Monitoring and auditing of employee } \\
\text { compliance with code of conduct }\end{array}$ & $43.53 \%$ & $48.84 \%$ \\
\hline 9 & $\begin{array}{l}\text { Incentive policies to uphold the code of } \\
\text { conduct }\end{array}$ & $23.20 \%$ & $24.92 \%$ \\
\hline
\end{tabular}

In 2004 and 2008, a 'code of ethics' was the most widely implemented of all of the components. In $2008,81.62 \%$ of the respondents indicated that their organization had a code of ethics. One other component that existed in 2008 in more than three quarters of the organizations was 'communication and training to employees on code of conduct' (i.e., 76.34\%). Components that were embedded in 2008 by about two thirds of the organizations were "policies to hold employees accountable for code of conduct violations' (70.98\%), 'policies to investigate and take corrective action if misconduct is alleged' (70.64\%), and 'background investigations on prospective employees' (66.52\%). In 2008, the following three components were embedded in more or less half the organizations: 'confidential and anonymous ethics hotline' (57.44\%), 'senior-level ethics or compliance officer' (56.15\%), and 'monitoring and auditing of employee compliance with code of conduct' $(48.84 \%)$. Less than a quarter of the organizations 
had embedded 'incentive policies to uphold the code of conduct' (24.92\%). In 2008, the average scope of ethics programs was 5.52.

TABLE 3

Change of Components of Ethics Programs between 2004 and 2008

\begin{tabular}{|c|c|c|c|}
\hline & & $\begin{array}{l}\text { Relative } \\
\text { change }\end{array}$ & $\begin{array}{l}\text { Absolute } \\
\text { change }\end{array}$ \\
\hline 1 & Confidential and anonymous ethics hotline & $+20.44 \%$ & $+9.75 \% * *$ \\
\hline 2 & $\begin{array}{l}\text { Communication and training to employees on code } \\
\text { of conduct }\end{array}$ & $+10.67 \%$ & $+7.36 \% * *$ \\
\hline 3 & Background investigations on prospective employees & $+10.96 \%$ & $+6.57 \% * *$ \\
\hline 4 & $\begin{array}{l}\text { Policies to hold employees accountable for code of } \\
\text { conduct violations }\end{array}$ & $+9.83 \%$ & $+6.35 \% * *$ \\
\hline 5 & $\begin{array}{l}\text { Policies to investigate and take corrective action if } \\
\text { misconduct is alleged }\end{array}$ & $+8.93 \%$ & $+5.79 \% * *$ \\
\hline 6 & $\begin{array}{l}\text { Monitoring and auditing of employee compliance } \\
\text { with code of conduct }\end{array}$ & $+12.20 \%$ & $+5.31 \% * *$ \\
\hline 7 & Senior-level ethics or compliance officer & $+9.56 \%$ & $+4.90 \% * *$ \\
\hline 8 & $\begin{array}{l}\text { Code of ethics that articulates the values and } \\
\text { standards of the organization }\end{array}$ & $+5.64 \%$ & $+4.36 \% * *$ \\
\hline 9 & Incentive policies to uphold the code of conduct & $+7.41 \%$ & $+1.72 \%^{\dagger}$ \\
\hline
\end{tabular}

${ }^{\dagger} \mathrm{p}<.1 \quad * \mathrm{p}<.05 \quad * * \mathrm{p}<.01$

In 2008, all components were more widely embedded in U.S. organizations than in 2004. The highest absolute increase was in 'ethics hotlines'. The percentage of organizations with an ethics hotline increased from $47.69 \%$ in 2004 to $57.44 \%$ in 2008 , amounting to an absolute increase of $9.75 \%$ and a relative increase of $20.44 \%$. The second highest increase was found in 'communication and training on code of conduct': from $68.98 \%$ in 2004 to $76.34 \%$ in 2008 , which translates into an absolute increase of $7.36 \%$ and a relative increase of $10.67 \%$. Six other components increased between $4.36 \%$ ('code of ethics') and $6.57 \%$ ('background investigations on prospective employees') more organizations. 'Incentive policies to uphold the code of conduct', which was least embedded both in 2004 and 2008, also exhibited the lowest absolute 
increase: $1.72 \%$. Overall, the scope of ethics programs showed a significant and substantial increase of 0.65 : from 4.87 to 5.52 .

\section{Ethical culture}

As is shown in Table 4, clarity was most visibly embedded in U.S. organizations. In 2008, the average level of clarity among respondents was $82.73 \%$. Supportability and congruency of supervisors scored about $75 \%$ in U.S. organizations. Congruency of management was slightly lower than congruency of supervisors: i.e. $69.56 \%$. Discussability was almost as embedded in U.S. organizations as congruency of management: $68.29 \%$. Sanctionability and feasibility scored just above 63\%: $63.72 \%$ and $63.22 \%$ respectively. With a score of $58.80 \%$, transparency was least embedded. In 2008, the overall embeddedment of the eight virtues was $68.42 \%$.

\section{TABLE 4}

Dimensions of Ethical Culture in 1999, 2004 and 2008

\begin{tabular}{|c|c|c|c|c|c|}
\hline & & 1999 & 2004 & 2008 & Average \\
\hline 1 & Clarity & $74.92 \%$ & $81.20 \%$ & $82.73 \%$ & $79.62 \%$ \\
\hline 2 & Supportability & $73.30 \%$ & $76.76 \%$ & $75.67 \%$ & $75.24 \%$ \\
\hline 3 & $\begin{array}{l}\text { Congruency } \\
\text { supervisors }\end{array}$ & $71.27 \%$ & $75.89 \%$ & $75.15 \%$ & $74.11 \%$ \\
\hline 4 & $\begin{array}{l}\text { Congruency } \\
\text { management }\end{array}$ & $65.93 \%$ & $69.20 \%$ & $69.56 \%$ & $68.23 \%$ \\
\hline 5 & Discussability & $67.72 \%$ & $68.92 \%$ & $68.29 \%$ & $68.31 \%$ \\
\hline 6 & Sanctionability & $58.59 \%$ & $64.33 \%$ & $63.72 \%$ & $62.21 \%$ \\
\hline 7 & Feasibility & $58.18 \%$ & $63.80 \%$ & $63.22 \%$ & $61.73 \%$ \\
\hline \multirow[t]{2}{*}{8} & Transparency & $56.15 \%$ & $58.77 \%$ & $58.80 \%$ & $57.91 \%$ \\
\hline & Average & $63.94 \%$ & $67.20 \%$ & $66.62 \%$ & $68.42 \%$ \\
\hline
\end{tabular}


As shown in Table 5, the embeddedness of all virtues improved significantly between 1999 and 2004. Relative to the other virtues, the virtues of sanctionability (9.80\%), feasibility (9.67\%) and clarity (8.38\%) improved most. Discussability improved least (1.77\%). Between 2004 and 2008, only clarity improved significantly $(1.88 \%)$ and discussability even decreased significantly $(-0.92 \%)$. All other virtues remained more or less unchanged. Between 1999 and 2008, clarity improved most $(10.42 \%)$ and discussability least $(0.84 \%)$.

\section{TABLE 5}

Relative and Absolute Change in Dimensions of Ethical Culture between 1999, 2004 and $2008 \dagger$

\begin{tabular}{llccc}
\hline & & $\mathbf{1 9 9 9 - 2 0 0 4}$ & $\mathbf{2 0 0 4 - 2 0 0 8}$ & $\mathbf{1 9 9 9 - 2 0 0 8}$ \\
\hline 1 & Clarity & $+8.38 \% * *$ & $+1.88 \% * *$ & $+10.42 \% \%^{* *}$ \\
& & $(+6.28 \%)$ & $(+1.53 \%)$ & $(+7.81 \%)$ \\
2 & Sanctionability & $+9.80 \% * *$ & $-0.96 \%$ & $+8.75 \% * *$ \\
& & $(+5.74 \%)$ & $(-0.61 \%)$ & $(+5.13 \%)$ \\
3 & Feasibility & $+9.67 \% * *$ & $-0.91 \%$ & $+8.67 \% * *$ \\
& & $(+5.62 \%)$ & $(-0.58 \%)$ & $(+5.04 \%)$ \\
4 & Congruency & $+4.96 \% * *$ & $+0.52 \%$ & $+5.50 \% * *$ \\
& management & $(+3.27 \%)$ & $(+0.36 \%)$ & $(+3.63 \%)$ \\
5 & Congruency & $+6.49 \% * *$ & $-0.97 \%$ & $+5.45 \% * *$ \\
& supervisors & $(+4.62 \%)$ & $(-0.74 \%)$ & $(+3.88 \%)$ \\
6 & Transparency & $+4.67 \% * *$ & $+0.04 \%$ & $+4.71 \% * *$ \\
& & $(+2.62 \%)$ & $(+0.03 \%)$ & $(+2.65 \%)$ \\
7 & Supportability & $+4.72 \% * *$ & $-1.43 \%$ & $+3.22 \% * *$ \\
& & $(+3.46 \%)$ & $(-1.09 \%)$ & $(+2.37 \%)$ \\
8 & Discussability & $+1.77 \% * *$ & $-0.92 \% *$ & $+0.84 \% * *$ \\
& & $(+1.20 \%)$ & $(-0.63 \%)$ & $(+0.57 \%)$ \\
& Average & $+6.31 \% * *$ & $-0.34 \%$ & $+5.95 \% * *$ \\
& & $(+3.26 \%)$ & $(+0.58 \%)$ & $(+2.68 \%)$ \\
\hline
\end{tabular}

$\dagger$ The relative change is presented between brackets

$* \mathrm{p}<.05 \quad * * \mathrm{p}<.01$ 
Unethical behavior

Table 6 depicts the percentage of respondents who had personally observed or had first-hand knowledge of the given type of unethical behavior occurring during the past twelve months (combining the scores for rarely, sometimes, often, and (almost) always).

TABLE 6

Unethical Behavior in 2004 and $2008^{11}$

\begin{tabular}{llcc}
\hline & & $\mathbf{2 0 0 4}$ & $\mathbf{2 0 0 8}$ \\
\hline 1 & Wasting, mismanaging, or abusing organizational resources & $44.09 \%$ & $45.68 \%$ \\
2 & Discriminating against employees & $39.85 \%$ & $39.23 \%$ \\
3 & Violating workplace health and safety rules or principles & $34.13 \%$ & $34.74 \%$ \\
4 & Engaging in (sexual) harassment or creating a hostile work & & \\
& environment & $31.69 \%$ & $30.92 \%$ \\
5 & Breaching employee privacy & $30.99 \%$ & $28.20 \%$ \\
6 & Violating employee wage, overtime, or benefits rules & $30.89 \%$ & $27.65 \%$ \\
7 & Mishandling confidential or proprietary information & $23.97 \%$ & $22.93 \%$ \\
8 & Engaging in activities that pose a conflict of interest & $23.42 \%$ & $21.89 \%$ \\
9 & Falsifying time and expense reports & $23.61 \%$ & $21.18 \%$ \\
10 & Violating document retention rules & $19.51 \%$ & $20.73 \%$ \\
11 & Engaging in false or deceptive sales and marketing practices & $26.96 \%$ & $20.31 \%$ \\
12 & Breaching computer, network, or database controls & $20.83 \%$ & $19.26 \%$ \\
13 & Stealing or misappropriating assets & $18.87 \%$ & $18.37 \%$ \\
14 & Violating environmental standards or regulations & $20.49 \%$ & $18.11 \%$ \\
15 & Entering into customer contracts relationships without the & & \\
& proper terms, conditions or approvals & $21.09 \%$ & $16.77 \%$ \\
16 & Breaching customer or consumer privacy & $21.55 \%$ & $16.67 \%$ \\
17 & Violating contract terms with customers & $17.50 \%$ & $14.97 \%$ \\
18 & Accepting inappropriate gifts, favors, entertainment, or & & \\
& kickbacks from suppliers & $17.12 \%$ & $14.96 \%$ \\
19 & Making false or misleading claims to the public or media & $18.54 \%$ & $14.61 \%$ \\
20 & Fabricating or manipulation product quality or safety test & & \\
& results & $14.23 \%$ & $13.77 \%$ \\
21 & Exposing the public to safety risk & $16.45 \%$ & $13.57 \%$ \\
22 & Improperly gathering competitors' confidential information & $15.89 \%$ & $12.93 \%$ \\
23 & Violating or circumventing supplier selection rules & $14.41 \%$ & $12.74 \%$ \\
24 & Falsifying or manipulating financial reporting information & $13.78 \%$ & $11.40 \%$ \\
25 & Engaging in anticompetitive practices & $13.75 \%$ & $11.14 \%$ \\
26 & Entering into supplier contracts that lack proper terms, & & \\
& conditions, or approvals & $12.60 \%$ & $10.90 \%$ \\
27 & Doing business with disreputable suppliers & $11.16 \%$ & $10.54 \%$
\end{tabular}


28 Providing regulators with false or misleading information

$12.43 \% \quad 10.41 \%$

29 Submitting false or misleading invoices to customers

$13.14 \% \quad 10.09 \%$

30 Violating contract or payment terms with suppliers

$11.24 \% \quad 9.41 \%$

31 Providing inappropriate information to analysts and investors

32 Violating the intellectual property rights or confidential information of suppliers

33 Paying suppliers without accurate invoices or records

34 Trading securities based on inside information

35 Violating international labor or human rights

36 Making improper political or financial contributions to domestic or foreign officials

37 Doing business with third parties that may be involved in money laundering or are prohibited under international trade restrictions and embargos ${ }^{12}$

Wasting, mismanaging, or abusing organizational resources was the most frequently observed unethical behavior in 2008 (45.68\%). Discriminating against employees (on the basis of age, race, gender, religious belief, sexual orientation, etc.) followed in second place (39.23\%), and violating workplace health and safety rules or principles, in third place $(34.74 \%)$. (Sexual) harassment or creating a hostile work environment (e.g., intimidation, racism, pestering, verbal abuse, and physical violence) was observed by more than $30 \%$ of the respondents $(30.92 \%)$. Between $20 \%$ and $30 \%$ of the respondents observed 7 types of unethical behavior, between $10 \%$ and $20 \%$ observed 18 types, and less than $10 \%$ observed 8 types of unethical behavior. Of the 37 types of unethical behavior, 'Doing business with third parties that may be involved in money laundering or are prohibited under international trade restrictions and embargos' had the lowest score at $4.12 \%$. 
TABLE 7

Relative and Absolute Change in Unethical Behavior between 2004 and 2008

\begin{tabular}{|c|c|c|c|}
\hline & & $\begin{array}{l}\text { Relative } \\
\text { change }\end{array}$ & $\begin{array}{c}\text { Absolute } \\
\text { change }\end{array}$ \\
\hline 1 & $\begin{array}{l}\text { Engaging in false or deceptive sales and marketing } \\
\text { practices }\end{array}$ & $-24.67 \%$ & $-6.65 \% * *$ \\
\hline 2 & Breaching customer or consumer privacy & $-22.65 \%$ & $-4.88 \% * *$ \\
\hline 3 & $\begin{array}{l}\text { Entering into customer contracts relationships without the } \\
\text { proper terms, conditions or approvals }\end{array}$ & $-20.48 \%$ & $-4.32 \% * *$ \\
\hline 4 & Violating employee wage, overtime, or benefits rules & $-10.49 \%$ & $-3.24 \% * *$ \\
\hline 5 & Making false or misleading claims to the public or media & $-21.20 \%$ & $-3.92 \% * *$ \\
\hline 6 & Submitting false or misleading invoices to customers & $-23.21 \%$ & $-3.05 \% * *$ \\
\hline 7 & Exposing the public to safety risk & $-17.51 \%$ & $-2.88 \% * *$ \\
\hline 8 & Breaching employee privacy & $-9.00 \%$ & $-2.79 \% * *$ \\
\hline 9 & $\begin{array}{l}\text { Improperly gathering competitors' confidential } \\
\text { information }\end{array}$ & $-18.63 \%$ & $-2.96 \% * *$ \\
\hline 10 & Engaging in anticompetitive practices & $-18.98 \%$ & $-2.61 \% * *$ \\
\hline 11 & Violating contract terms with customers & $-14.46 \%$ & $-2.53 \% * *$ \\
\hline 12 & Falsifying time and expense reports & $-10.29 \%$ & $-2.43 \% * *$ \\
\hline 13 & Falsifying or manipulating financial reporting information & $-17.27 \%$ & $-2.38 \% * *$ \\
\hline 14 & Violating environmental standards or regulations & $-11.62 \%$ & $-2.38 \% * *$ \\
\hline 15 & $\begin{array}{l}\text { Providing inappropriate information to analysts and } \\
\text { investors }\end{array}$ & $-19.24 \%$ & $-2.22 \% * *$ \\
\hline 16 & Accepting inappropriate gifts, favors, entertainment, or & & \\
\hline & kickbacks from suppliers & $-12.62 \%$ & $-2.16 \% * *$ \\
\hline 17 & Providing regulators with false or misleading information & $-16.25 \%$ & $-2.02 \% * *$ \\
\hline 18 & Violating contract or payment terms with suppliers & $-16.28 \%$ & $-1.83 \% * *$ \\
\hline 19 & $\begin{array}{l}\text { Entering into supplier contracts that lack proper terms, } \\
\text { conditions, or approvals }\end{array}$ & $-13.49 \%$ & $-1.70 \% * *$ \\
\hline 20 & Violating or circumventing supplier selection rules & $-11.59 \%$ & $-1.67 \% * *$ \\
\hline 21 & Paying suppliers without accurate invoices or records & $-16.97 \%$ & $-1.60 \% * *$ \\
\hline 22 & Breaching computer, network, or database controls & $-7.54 \%$ & $-1.57 \% * *$ \\
\hline 23 & $\begin{array}{l}\text { Making improper political or financial contributions to } \\
\text { domestic or foreign officials }\end{array}$ & $-21.68 \%$ & $-1.55 \% * *$ \\
\hline 24 & Engaging in activities that pose a conflict of interest & $-6.53 \%$ & $-1.53 \% * *$ \\
\hline 25 & Trading securities based on inside information & $-18.67 \%$ & $-1.51 \% * *$ \\
\hline 26 & Violating international labor or human rights & $-15.86 \%$ & $-1.21 \% * *$ \\
\hline 27 & Mishandling confidential or proprietary information & $-4.34 \%$ & $-1.04 \% *$ \\
\hline 28 & $\begin{array}{l}\text { Violating the intellectual property rights or confidential } \\
\text { information of suppliers }\end{array}$ & $-10.71 \%$ & $-1.03 \% * *$ \\
\hline 29 & $\begin{array}{l}\text { Doing business with third parties that may be involved in } \\
\text { money laundering or are prohibited under international } \\
\text { trade restrictions and embargos }\end{array}$ & $-16.43 \%$ & $-0.81 \% *$ \\
\hline 30 & $\begin{array}{l}\text { Engaging in (sexual) harassment or creating a hostile } \\
\text { work environment }\end{array}$ & $-2.43 \%$ & $-0.77 \%$ \\
\hline
\end{tabular}


31 Doing business with disreputable suppliers

$-5.56 \%-0.62 \%{ }^{\dagger}$

32 Discriminating against employees

$-1.56 \%-0.62 \%$

33 Stealing or misappropriating assets

$-2.65 \% \quad-0.50 \%$

34 Fabricating or manipulation product quality or safety test results

$-3.23 \% \quad-0.46 \%$

$+1.79 \%+0.61 \%$

35 Violating workplace health and safety rules or principles

36 Violating document retention rules

$+6.25 \%+1.22 \% * *$

37 Wasting, mismanaging, or abusing organizational resources

$+3.61 \%+1.59 \% * *$

${ }^{\dagger} \mathrm{p}<.1 \quad * \mathrm{p}<.05 \quad * * \mathrm{p}<.01$

Regarding the increase in unethical behavior as perceived by the respondents, only two types of unethical behavior increased in 2008 compared to 2004: 'wasting, mismanaging, or abusing organizational resources' increased by $1.59 \%$ (and relatively by $3.61 \%$ ) and 'violating document retention rules' increased significantly by $1.22 \%$ (and relatively by $6.25 \%$ ). Thirty types of unethical behaviors were observed significantly less frequently in 2008 compared to 2004. In absolute and relative terms, 'engaging in false or deceptive sales and marketing practices' declined most markedly (by $6.65 \%$ and $24.67 \%$ respectively). The majority of unethical behaviors, i.e. 22 of the 37 behaviors, decreased in absolute terms by $1 \%-3 \%$.

Clustering the types of unethical behavior by stakeholder category, as depicted in Table 8, shows that in 2008 unethical behavior toward employees was observed most frequently. This increase applies both in terms of percentage of respondents who had perceived at least one type of unethical behavior in this cluster (53.99\%) and the average increase within the entire cluster (32.15\%). At least one type of unethical behavior toward financiers (comprising ten different types) was witnessed by more than $50 \%$ of the respondents $(52.69 \%)$. Unethical behavior toward suppliers and society was perceived least frequently.

Comparing the results of 2008 with 2004 shows that unethical behavior toward financiers increased in absolute terms by $1.04 \%$, which was insignificant. All other 
categories decreased significantly, with unethical behavior toward customers scoring highest (from $42.08 \%$ by $8.08 \%$ to $34.00 \%$ ). The percentage of respondents that observed at least one type of unethical behavior in the past twelve months decreased slightly: from $71.10 \%$ in 2004 by 2.80 to $68.30 \%$ in $2008 .^{13}$

TABLE 8

Aggregate Change in Unethical Behavior between 2004 and 2008†

\begin{tabular}{llccc}
\hline Unethical behavior toward & $\mathbf{2 0 0 4}$ & $\mathbf{2 0 0 8}$ & $\begin{array}{c}\text { Absolute } \\
\text { change }\end{array}$ \\
\hline 1 & Customers & $42.08 \%$ & $34.00 \%$ & $-8.08 \%^{* *}$ \\
2 & Society & $(18.10 \%)$ & $(14.58 \%)$ & $(-3.43 \%)$ \\
& & $30.73 \%$ & $25.11 \%$ & $-5.62 \% *$ \\
3 & Suppliers & $(11.08 \%)$ & $(9.18 \%)$ & $(-1.90 \%)$ \\
& & $25.31 \%$ & $23.50 \%$ & $-1.81 \%^{\dagger}$ \\
4 & Employees & $(12.23 \%)$ & $(10.71 \%)$ & $(-1.52 \%)$ \\
& & $55.75 \%$ & $53.99 \%$ & $-1.76 \%{ }^{\dagger}$ \\
5 & Financiers & $(33.51 \%)$ & $(32.15 \%)$ & $(-1.36 \%)$ \\
& & $51.65 \%$ & $52.69 \%$ & $+1.04 \%$ \\
\end{tabular}

$\dagger$ Without brackets is the percentage of respondents who observed at least one type of unethical behavior for that particular stakeholder category. Between brackets is the average percentage of observed unethical behavior for the category.

${ }^{\dagger} \mathrm{p}<.1 \quad * \mathrm{p}<.05 \quad * * \mathrm{p}<.01$

Effects

Table 9 displays the percentage of respondents that indicated the potential consequences of unethical behavior they had observed during the last twelve months. In 2004 and in 2008, 'significant loss of new of employee morale or productivity' was perceived as the most likely consequence. All four potential consequences were considered significantly less likely in 2008 than in $2004 .^{14}$ 
TABLE 9

Perceived Potential Effects of Unethical Behavior in 2004 and 2008

\begin{tabular}{|c|c|c|c|c|c|}
\hline & & 2004 & 2008 & $\begin{array}{l}\text { Relative } \\
\text { change }\end{array}$ & $\begin{array}{l}\text { Absolute } \\
\text { change }\end{array}$ \\
\hline 1 & $\begin{array}{l}\text { Significant loss of new or } \\
\text { existing customers }\end{array}$ & $46.00 \%$ & $41.50 \%$ & $-9.78 \%$ & $-4.50 \% * *$ \\
\hline 2 & Significant loss of public trust & $50.50 \%$ & $46.20 \%$ & $-8.51 \%$ & $-4.30 \% * *$ \\
\hline 3 & $\begin{array}{l}\text { Significant legal fines or } \\
\text { sanctions }\end{array}$ & $46.60 \%$ & $43.40 \%$ & $-6.87 \%$ & $-3.20 * *$ \\
\hline 4 & $\begin{array}{l}\text { Significant loss of employee } \\
\text { morale or productivity }\end{array}$ & $59.90 \%$ & $57.70 \%$ & $-3.67 \%$ & $-2.20 \%{ }^{\dagger}$ \\
\hline
\end{tabular}

${ }^{\dagger} \mathrm{p}<.1 \quad * \mathrm{p}<.05 \quad * * \mathrm{p}<.01$

Whereas Table 9 reports the negative impact of observed unethical behavior, Table 10 depicts the percentage of respondents who noted a favorable stakeholder view of the ethics and integrity of the organization. In 2008, customers had the most favorable $(74.37 \%)$ and suppliers the least favorable $(66.94 \%)$ view of the organization's ethics. The average views were within close range. Comparing the results of 2008 with 2004 shows that the view of society and suppliers improved significantly: from $67.05 \%$ in 2004 to $69.08 \%$ in 2008 for society and from $65.14 \%$ in 2004 to $66.94 \%$ in 2008 for suppliers.

TABLE 10

Perceived Favorable Stakeholder View of the Ethics of Organizations in 2004 and 2008

\begin{tabular}{llcccc}
\hline & $\mathbf{2 0 0 4}$ & $\mathbf{2 0 0 8}$ & $\begin{array}{c}\text { Relative } \\
\text { change }\end{array}$ & $\begin{array}{c}\text { Absolute } \\
\text { change }\end{array}$ \\
\hline 1 & Society & $67.05 \%$ & $69.08 \%$ & $3.03 \%$ & $+2.03 \%{ }^{*}$ \\
2 & Suppliers & $65.14 \%$ & $66.94 \%$ & $2.76 \%$ & $+1.80 \%^{\dagger}$
\end{tabular}




\begin{tabular}{llrrrr}
3 & Financiers & $71.40 \%$ & $72.63 \%$ & $1.72 \%$ & $+1.23 \%$ \\
4 & Customers & $73.28 \%$ & $74.37 \%$ & $1.49 \%$ & $+1.09 \%$ \\
5 & Employees & $73.60 \%$ & $72.80 \%$ & $-1.09 \%$ & $-0.81 \%$ \\
\hline & & & &
\end{tabular}

\section{SUMMARY}

This paper reported the findings of a longitudinal study of the U.S. working population in 1999, 2004 and 2008. A large dataset consisting of 12,196 respondents was used. The utilization of scientifically developed models for both ethical culture and unethical behavior made it possible to conduct a unique study, yielding some interesting findings, which will be discussed below.

Three measurements of the eight dimensions of the ethical culture of organizations were taken into account in this study. On average, all dimensions improved between 1999 and 2004. Clarity was the only dimension that improved significantly between 2004 and 2008. Most other dimensions actually decreased slightly although not significantly between 2004 and 2008. Clarity was also the dimension that improved most between 1999 and 2008 - both in relative and absolute terms - while discussability showed the least improvement.

Measurements of the components of an ethics program took place twice, in 2004 and 2008. A code of ethics was adopted in most organizations in 2004 and 2008. In 2008, the level at which each component was adopted, exceeded that of 2004. Between 2004 and 2008, the relative and absolute increase in the adoption of the components varied markedly. The adoption of an ethics hotline increased most in absolute and relative terms. In absolute terms, the adoption of incentive policies to uphold the code 
of conduct increased least, whereas the adoption of a code of ethics showed the lowest relative increase.

This study involved three measurements of the frequency of unethical behavior. However, as the first measurement did not use an extensively developed and tested scale, the findings of 1999 could not be compared with 2004 and 2008, when a better scale was used. Between 2004 and 2008, an overall decline in perceived unethical behavior was found. The following six types of unethical behavior showed a relative decrease of more than 20\%: 'engaging in false or deceptive sales and marketing practices', 'breaching customer or consumer privacy', 'entering into customer contracts relationships without the proper terms, conditions or approvals', 'making false or misleading claims to the public or media', 'submitting false or misleading invoices to customers', and 'making improper political or financial contributions to domestic or foreign officials'. Only the frequency of 'violating document retention rules' and 'wasting, mismanaging, or abusing organizational resources' increased between 2004 and 2008. Clustering the types of unethical behavior toward stakeholders showed that in absolute terms, unethical behavior toward customers decreased most between 2004 and 2008, whereas unethical behavior toward financiers increased, although not significantly.

All four potentially negative effects of unethical behavior on organizations decreased between 2004 and 2008. Regarding stakeholders' view of the ethics of their organization, four of the five stakeholder groups were perceived to be more positive in 2008 than in 2004, suppliers and society being at the top of the list. Favorable views of employees, however, decreased in absolute terms by almost $1 \%$. 


\section{DISCUSSION}

How can the findings of this study be accounted for? Several reasons can be advanced for the increase in the scope of ethics programs between 2004 and 2008. Legal and stakeholder pressure and the advantages of implementing an effective ethics program have increased. Experience and best practices have become more accessible and are more widely exchanged due to the growth of relevant networks and associations, (e.g., the Ethics \& Compliance Officer Association), conferences and seminars that are organized in this field, and the publication of new scientific studies on the importance of ethics programs (e.g., Joseph, 2002; Treviño and Weaver, 2003). Furthermore, it would not be prudent to abolish components of an ethics program. For example, doing away with one component such as a code of ethics would be met with indignation from stakeholders (Kaptein, 2008c). The number of components of an ethics program is therefore more likely to expand than to shrink.

More difficult to explain is why, apart from clarity, all dimensions of the ethical culture of organizations improved between 1999 and 2004 and not between 2004 and 2008. One would expect that an increase in the scope of ethics programs in a given period would simultaneously be accompanied by the enhancement of the ethical culture. That clarity improved between 2004 and 2008 can be explained by the fact that several components of an ethics program, such as code of ethics and policies on accountability, sanctions, and investigations, are largely aimed at enhancing clarity (Kaptein, 2009). The decline in unethical behavior between 2004 and 2008, could lead one to conclude that the more components of an ethics program exist, the lower the perceived unethical behavior, and thus that ethical culture has no impact on unethical behavior at all. To verify this interpretation, a regression analysis was conducted. 
As control variables the hierarchical position, age, gender and organizational size were used. When the scope of ethics programs was added to the control variables, the adjusted $\mathrm{R}^{2}$ increased with 0.08 , which implies that ethics programs explained 8 percent of unethical behavior. Adding the eight virtues as dimensions of ethical culture resulted in an increase of the adjusted $\mathrm{R}^{2}$ by 0.257 , implying that ethical culture on its own explained 25.7 percent of unethical behavior. When the eight dimensions of ethical culture were added directly after the control variables, the adjusted $\Delta \mathrm{R}^{2}$ was even higher, at 0.336 . After adding the scope of ethics programs the adjusted $\mathrm{R}^{2}$ increased by only 0.01 .

Ethical culture thus has a high explanatory value. But would this mean that the value of ethics programs is limited to only, in the second analysis, one percent of unethical behavior? Another possibility is that ethics programs, as depicted in Figure 1, do not only have a direct impact on unethical behavior, but also - and especially - an indirect impact via ethical culture. To examine this indirect relationship, a regression analysis was performed using ethics programs as independent variable and ethical culture as dependent variable, and using the same control variables as in the first regression analysis. The scope of an ethics program was significantly related to ethical culture $(\beta=0.447)$, with an adjusted $\Delta \mathrm{R}^{2}$ of 0.198 . So the results seem to indicate that the impact of ethics programs on unethical behavior in and of organizations is more indirect than direct.

But how do we reconcile the increase in the scope of ethics programs between 2004 and 2008 with the fact that there was no significant change in the seven dimensions of ethical culture in this period? A possible explanation is that although the scope of ethics programs increased, the relationship with ethical culture became weaker since organizations that adopted an ethics program at a later stage were more likely to 
be motivated by extrinsic reasons than the early adopters who were more likely to be motivated by intrinsic reasons to improve their ethical culture. When we compare the explanatory value of ethics program for ethical culture in both measurements, the $\Delta \mathrm{R}^{2}$ in 2004 was 0.190 (with $\beta=0.439$ ) and the $\Delta \mathrm{R}^{2}$ in 2008 was .203 (with $\beta=0.456$ ). This finding does not suggest that the relationship weakened. Further research will have to be conducted to determine how the scope of ethics programs could increase without leading to an improvement in ethical culture.

The question as to why unethical behavior decreased between 2004 and 2008 while ethical culture remained almost unchanged during the same period is also relevant. A possible explanation is that it took some time for the improvements in the ethical culture between 1999 and 2004 to manifest in a decrease in unethical behavior. This delay or time lag effect may have occurred because improvements in ethical culture do not necessarily directly and fully translate to improved behavior, especially since unethical behavior is not a daily or everyday occurrence (at least not in most organizations). ${ }^{15}$ Such time lag effects have also been found in the relationship between reputation and credibility and brand success (Herbig and Milewicz, 1997), between investments in information technology and market value (Im, Dow, and Grover, 2001), between advertising and goodwill (Luhta and Virtanen, 1996), between the organizational learning culture and financial performance (Škerlavaj, Štemberger, Škrinjar, and Dimovski, 2007) and between human resources management and organizational performance (Hailey, Farndale, and Truss, 2005). Another, complementary, explanation is that other factors could be responsible for the decline in unethical behavior. The regression analysis showed that about two thirds of unethical behavior in and of organizations could not be attributed to ethical culture and ethics programs. Future research could be conducted to identify other factors that explain (the 
change in) unethical behavior, such as the factors suggested by Baucus and Near (1991), Greenberg (2002), Jones (1991), and Treviño (1986).

\section{Limitations and Research Implications}

This study has its limitations, four of which will be discussed here. The first limitation is related to the scales and measures used. Unfortunately, the study lacked useable data for the scope of ethics programs and frequency of unethical behavior for 1999. Due to this lack of information a more in-depth comparison with 2004 and 2008 was not possible. Although the questionnaire we used contained important scales for the ethics of an organization, other scales were not included. For example, a measure for the ethical climate of an organization, such as developed by Victor and Cullen (1987, 1888), was not integrated into the questionnaire due to limited space. The manner in which the construct of ethical program was operationalized is also limited. Only nine components of an ethics program in the organization were included. Including more components could have increased the explanatory value of this construct. Adding questions about the quality, intensity, and coherence of these components could further enhance our understanding of the implementation of and developments in ethics programs and, as such, increase the explanatory value of this construct.

The second limitation concerns the moments of measurement and their frequency. The intervals between the measurements were not identical, about five years and 3.5 years respectively, with the result that significant changes were more likely to be registered in the first than in the second period. Ideally, the intervals should be identical in order to compare the findings accurately. Furthermore, measuring the ethics of organizations more frequently, for example biannually, would improve our 
knowledge and understanding of developments. Measuring the ethics of organizations over a longer period (as the Ethics Resource Center (2007) does) than the almost 9 year span of this study will also increase our understanding of the developments of the ethics of organizations.

A third limitation concerns the quality of the data. The data collected was not panel data in the strict sense of the term: the same people did not participate in each study. Although panel data could have increased the quality of the data, access to the same respondents reporting about the same organization over a period of ten years simply is not practicable. Respondents change employers, functions, jobs, teams and hierarchical levels. Over a period of ten years' time, a large number of people stop working and another group starts working. The results also do not pretend to be representative of the entire U.S. working population. Respondents were selected from organizations with more than 200 employees and from eleven industries. Collecting a representative database for the full U.S. working population was, due to time and budget constraints, beyond the scope of this study. However, it would be interesting to examine the status of the ethics of organizations with less than 200 employees and the kind of developments that take place in this segment of the economy. It would of course also be interesting to conduct similar studies in other countries and to identify similarities and differences.

A fourth limitation is related to the methodology used in this study. As noted in the introduction of the paper, only one method was used to assess the ethics of organizations, i.e. a survey. Measuring perceptions is a meaningful approach to evaluating the ethics, and especially the ethical culture, of organizations. However, other types of data could also be used in order to obtain a richer understanding of the ethics of organizations. Data on ethics programs can also be obtained by interviewing 
ethics officers. Data on unethical behavior can also be obtained by examining the number of reported and recorded violations in organizations and, for example, the frequency and level of fines that are imposed by government authorities. The ethical reputation of an organization can also be examined by conducting interviews and surveys among external stakeholders.

Interesting questions about the findings that fall beyond the scope of this study, but that could be the object of future research are, for example, why the frequency of 'violating document retention rules' and 'wasting, mismanaging, or abusing organizational resources' increased between 2004 and 2008, and why decreased levels of unethical behavior toward customers and employees between 2004 and 2008 did not lead to more favorable views of these stakeholders of the ethics of the organization in that same period. Other relevant questions pertain to the exact relationship between the constructs that were studied in this paper, the most important components of ethics programs and the most significant dimensions of ethical culture.

\section{Practical Implications}

This paper hopefully illustrated the value of measuring and monitoring the ethics of organizations at national level. But individual organizations can also measure and monitor their ethics by conducting studies similar to the one discussed in this paper. Multiple measurements of the ethics of an organization will be especially useful in revealing developments and to assist boards in finding answers to questions like: 'Is our ethics program effective?', 'To what extent does our current organizational culture promote ethical behavior and deter unethical behavior?', and 'Do we know what type of behavior is occurring in our organization?' Through benchmarking an organization can 
monitor and compare its performance over time: internally, but also with other (similar) organizations as the relative strong and weak aspects of the ethics of the organization become visible.

Regarding the empirical findings, some dimensions of the ethical culture of organizations, such as transparency (58.80\%), feasibility (63.22\%) and sanctionability $(63.72 \%)$, did not score very high. Given the risks involved when these dimensions are insufficiently embedded in organizations, and given that in $200874 \%$ of the respondents witnessed at least one type of unethical behavior in their organization, it is important to consider measures and activities to improve these dimensions. Especially since the ethical culture of U.S. organizations generally has not improved between 2004 and 2008, even showing a slight, although not significant, decline, calls for new and innovative ways to develop the ethical culture of organizations.

On the one hand, it could be a matter of adopting more components of an ethics program as many organizations have not adopted all nine components that have been identified in this paper and are promoted by the U.S. Federal Sentencing Guidelines for Organizations. Only $15.60 \%$ of the respondents from our 2008 study indicated that all components had been adopted. Also, according to $18.38 \%$ of all respondents, the most widely used component of an ethics program, a code of ethics, still has not been adopted by their organization. On the other hand, it could be a matter of improving the quality and implementation of current components of ethics programs rather than adopting new components. Although detailed information about the quality and implementation of ethics programs is not available at present, organizations are advised to reflect critically on the effectiveness of their ethics program and the measures that can and should be taken to enhance its effectiveness. 
Given the importance of the internal hard and soft controls of an organization for preventing and detecting unethical behavior, embedding it in the planning and control cycle of the organization is one way to raise awareness of management to systematically work on it. External reporting on the internal hard and soft controls of an organization, and including it in the annual financial report is another way of focusing more attention on the ethical culture and ethics program of an organization. Based on Section 404 of the Sarbanes-Oxley Act, which requires companies and their auditors to evaluate the effectiveness of internal controls on financial reporting, organizations are already paying more attention to assessing the quality of their ethics program and ethical culture. Using advanced measurement models and being attentive to the relationship between ethics program, ethical culture and unethical behavior, a better understanding can be obtained of what works and what does not work. 


\section{REFERENCES}

Akaah, I. P.: 1996, 'The Influence of Organizational Rank and Role on Marketing Professionals' Ethical Judgments', Journal of Business Ethics 15: 605-13.

Aspen Institute, The: 2007, Beyond Grey Pinstripes 2007-2008 (Aspen Institute, New York).

Baucus, M. S. and J. P. Near: 1991, 'Can Illegal Corporate Behavior Be Predicted? An Event History Analysis', Academy of Management Journal 34, 9-36.

Berenbeim, R.: 1992, Corporate Ethics Programs (Conference Board, New York).

Co-operative Bank, The: 2007. The Ethical Consumerism Report 2007 (Co-operative Bank, Manchester).

Crane, A. and D. Matten: 2007, Business Ethics (Oxford University Press, New York).

Donaldson, T., and L. E. Preston: 1995, 'The Stakeholder Theory of the Corporation: Concepts, Evidence, and Implications', The Academy of Management Review 20: $65-91$.

Ethics Resource Center: 2007, Ethics Resource Center's National Business Ethics Survey: An Inside View of Private Sector Ethics (ERC, Arlington).

Ferrell, O. C., D. Thorne LeClair and L. Ferrell: 1998, 'The Federal Sentencing Guidelines for Organizations: A Framework for Ethical Compliance', Journal of Business Ethics 17: 353-63.

Freeman, R. E.: 1984, Strategic Management: A Stakeholder Approach (Pitman Marshfield, MA).

Greenberg, J.: 2002, 'Who Stole the Money, and When? Individual and Situational Determinants of Employee Theft', Organizational Behavior and Human Decision Processes 89, 985-1003. 
Harrison, R., T. Newholm and D. Shaw (Eds): 2005, The Ethical Consumer (Sage, London).

Hailey, V. H., E. Farndale and C. Truss: 2005, 'The HR Department's Role in Organizational Performance', Human Resource Management Journal 15, 3: 4966.

Herbig, P. and J. Milewicz: 1997, 'The Relationship of Reputation and Credibility to Brand Success', Pricing Strategy and Practice 5: 25-9.

Im, K. S., K. E. Dow and V. Grover: 2001, 'A Reexamination of IT Investment and the Market Value of the Firm: An Event Study Methodology', Information Systems Research 12: 103-17.

Jackson, T. M. and C. Artola: 1997, 'Ethical Beliefs and Management Behavior: A Cross-Cultural Comparison', Journal of Business Ethics 16: 1163-73.

Jones, T. M.: 1991, 'Ethical Decision Making by Individuals in Organizations: An Issue-Contingent Model', Academy of Management Review 16: 366-95.

Jones, T. M., W. Felps and G. A. Bigley: 2007, 'Ethical Theory and StakeholderRelated Decisions: The Role of Stakeholder Culture', The Academy of Management Review 32: 137-55.

Jones, T. M. and A. C. Wicks: 1999, 'Convergent Stakeholder Theory', The Academy of Management Review 24: 206-21.

Joseph, J.: 2002, 'Integrating Business Ethics and Compliance Programs: A Study of Ethics Officers in Leading Organizations', Business and Society Review 107, $309-47$.

Kaptein, M.: 1998, Ethics Management: Auditing and Developing the Ethical Content of Organizations (Springer, Dordrecht). 
Kaptein, M.: 2008a, 'Developing and Testing a Measure for the Ethical Culture of Organizations: The Corporate Ethical Virtues Model', Journal of Organizational Behavior 29, 923-47.

Kaptein, M.: 2008b, 'Development of a Measure of Unethical Behavior in the Workplace: A Stakeholder Perspective', Journal of Management 34, 978 - 1008.

Kaptein, M.: 2008c, The Living Code: Embedding Ethics into the Corporate DNA (Greenleaf, Sheffield).

Kaptein, M.: 2009, 'Ethics Programs and Ethical Culture: A Next Step in Unraveling Their Multi-Faceted Relationship', Journal of Business Ethics (forthcoming).

Kaptein, M. and J. Dalen, van: 2000, 'The Empirical Assessment of Corporate Ethics: A Case Study', Journal of Business Ethics 24, 95-114.

Kaptein, M. and J. Wempe: 2002, The Balanced Company: A Corporate Integrity Approach (Oxford University Press, Oxford).

KPMG: 2008, Business Code of the Global 200: Their Prevalence, Content and Embedding (KPMG, Amsterdam).

KPMG: 2009, Integrity Survey 2008-2009 (KPMG, Washington).

Luhta, I. and I. Virtanen: 1996, 'Non-linear Advertising on Goodwill Capital Model with Time Delayed Feedback between Advertising and Stock of Goodwill', Chaos, Solitons \& Fractals 7: 2083-99.

Mitchell, R. K., B. R. Agle and D. J. Wood: 1997, 'Toward a Theory of Stakeholder Identification and Salience: Defining the Principle of Who and What Really Counts', Academy of Management Review 22: 853-86.

Newstrom, J. W. and W. A. Ruch: 1975, 'The Ethics of Management and the Management of Ethics', MSU Business Topics 23: 29-37. 
Nielsen: 2008, Corporate Ethics and Fair Trading: A Nielsen Global Consumer Report (Nielsen, New York).

Nunally, J. C.: 1978, Psychometric Theory (McGraw-Hill, New York).

Škerlavaj, M., M. I., Štemberger, R. Škrinjar and V. Dimovski: 2007, 'Organizational Learning Culture: The Missing Link between Business Process Change and Organizational Performance', International Journal of Production Economics 106: 346-67.

Social Investment Forum: 2007, ‘2007 Report on Socially Responsible Investing Trends in the United States' (SIF, Washington).

Treviño, L. K.: 1986, 'Ethical Decision Making in Organizations: A Person-Situation Interactionist Model', Academy of Management Review 11, 601-17.

Treviño, L. K.: 2005, 'Out of Touch: The CEO's Role in Corporate Misbehavior', Brooklyn Law Review 70, 1195-211.

Treviño, L. K., K. D. Butterfield and D. L. McCabe: 1998, 'The Ethical Context in Organizations: Influences on Employee Attitudes and Behaviors', Business Ethics Quarterly 8, 447-76.

Treviño, L. K. and G. R. Weaver: 2003, Managing Ethics in Business Organizations: Social Scientific Perspectives (Stanford University Press, Stanford).

Treviño, L. K., G. R. Weaver and S. J. Reynolds: 2006, 'Behavioral Ethics in Organizations: A Review', Journal of Management 32: 951-90.

Victor, B. and J. B. Cullen: 1987, 'A Theory and Measure of Ethical Climate in Organizations', Research in Corporate Social Performance and Policy 9, 51-71.

Victor, B. and J. B. Cullen: 1988, ‘The Organizational Bases of Ethical Work Climates', Administrative Science Quarterly 33, 101-25. 
Weaver, G. R, L. K. Treviño and P. L. Cochran: 1999, 'Corporate Ethics programs as Control Systems: Influences of Executive Commitment and Environmental Factors', Academy of Management Journal 42, 41-57.

Zey-Ferrell, M. and O. C. Ferrell: 1982, 'Role-set Configuration and Opportunity as Predictors of Unethical Behavior in Organizations, Human Relations 35: 587604. 


\section{The Ethics of Organizations}

\section{NOTES}

${ }^{1}$ Many thanks to KPMG for funding the data collection for the research conducted in 1999, 2004 and
2008. Many thanks especially to Scott Avelino, principal at KPMG, for enabling and coordinating the data collections.

${ }^{2}$ The Ethics Resource Centre conducts similar survey studies of the U.S. working population. The study as discussed in this paper aims to make a contribution to understanding and managing the ethics of organizations by using scientific models and tested scales capturing relevant dimensions of ethical culture and unethical behaviour.

${ }^{3}$ Ethics programs and ethical culture can also be interrelated. Ethics programs can be aimed at improving and preserving the ethical culture of organizations. And ethical cultures can influence the content of ethics programs as well as facilitate and support the effectiveness of an ethics program and its impact on behaviour. The relationship between ethics programs and ethical culture is proposed in the discussion section of the paper as a promising direction for future research.

${ }^{4}$ The stakeholder model can also be used for the two other general ethical theories, i.e. to delineate duties and rights regarding the behaviour in and of organizations (deontological ethics) as well as desirable characteristics of organizations (virtue ethics), such as the typology of stakeholder cultures as proposed by Jones , Felps and Bigley (2007).

5 That, for example, unethical behavior can occur despite the sound intentions of an organization is recognized in the U.S. Federal Sentencing Guidelines for Organizations. Section $§ 8 B 2.1$ of the guidelines state that "The failure to prevent or detect the instant offense does not necessarily mean that the program is not generally effective in preventing and detecting criminal conduct."

${ }^{6}$ To measure the ethical culture of organizations, Version 2 of the so-called 'KPMG Ethics \& Integrity Thermometer' was used in this study. Version 1 is the questionnaire as developed and presented by Kaptein (1998) and Kaptein and Van Dalen (2000). Version 3 is the questionnaire as further developed and tested by Kaptein (2008a). The latter version was not used because it was not available at the time of data collection for the first two measurements. Using Version 3 only the third measurement would have reduced the feasibility of comparing the different measurements with each other. 


\section{The Ethics of Organizations}

${ }^{7}$ This dummy score for a missing question in 1999 was computed by calculating the average absolute change of the other questions for the cultural dimension between 1999 and 2004, which was then added to or subtracted from the score of that missing question in 2004. By doing this, the impact of the missing question on the average score of the dimension in 1999 was neutralized.

${ }^{8}$ In the questionnaire, the stakeholder dimension 'society' was split into two items: (1) regulators and (2) public/community. The presented results are the average percentages of these two items.

${ }^{9}$ The 2008 KPMG report on the results for that year shows some different frequencies for the components of ethics programs because the responses to the answer 'not applicable' were treated as missing values whereas in this paper these responses were considered as the absence of components and as such are included in the valid scores.

${ }^{10}$ In Kaptein (2009), which partly uses the data from the 2004 survey to analyze the relationship between ethics program and ethical culture, two percentages were erroneously swapped: the mean for 'training and communication' was reported in Table 1 in that paper as 0.60 which should have been 0.69 , whereas the mean for 'pre-employment screening' was reported as 0.69 which should have been 0.60 .

11 As explained, in the 1999 study other items were used. The results for these items were: false/misleading promises to customers (39\%), violation of workplace health/safety rules (37\%), employment discrimination (36\%), violation of employee rights to privacy (36\%), sexual harassment or hostile work environment (34\%), carelessness with confidential/proprietary information (31\%), activities posing a conflict of interest (21\%), false/misleading information to public or media (19\%), unfair competition/antitrust (18\%), substance abuse (19\%), environmental breaches (17\%), falsifying product quality/safety test results (14\%), offering improper gifts, favors or entertainment to influence others (14\%), shipping product that does not meeting quality/safety standards (13\%), dishonesty/unfair treatment of suppliers (13\%), falsification/improper manipulation of financial data (11\%), embezzling funds or stealing from the organization (10\%), making false/misleading statements to government regulators (9\%), false/misleading information to investors or creditors (9\%), trading company shares based on insider information (5\%), improper political contribution to domestic officials (4\%), and offering or paying bribes to foreign officials $(3 \%)$. The percentage of respondents that witnessed at least one unethical behavior during the last twelve months was 74.88 . 
${ }^{12}$ Following Kaptein (2008b), the score for this item is a contraction of two separate items in the questionnaire, 'Doing business with third parties that may be involved in money laundering' and 'Doing business with third parties that are prohibited under international trade restrictions and embargos'.

${ }^{13}$ The 2008 KPMG report on the results shows higher percentages of respondents having witnessed at least one type of unethical behaviour because more items were included in that list, such as 'violating my company's values and principles', which was omitted from the factor analysis performed by Kaptein (2008b) and therefore not included in the final scale.

${ }^{14}$ Comparing 1999 and 2004, with the disadvantage in mind that the list of unethical behaviour was different in these two measurements, shows that 'significant legal fines' as a potential effect increased between 1999 and 2004 from $42.84 \%$ by $3.15^{* *}$ to $46.01 \%$, indicating the more serious legal consequences of unethical behaviour, whereas 'loss of public trust' decreased from $48.88 \%$ by $-.2 .29 * *$ to $46.59 \%$.

${ }^{15}$ It is also possible that the change in ethical culture as witnessed in the period between 1999 and 2004 occurred just before the measurement took place at the end of 2004. Because the ethical culture questions are related to the current situation and the unethical behaviour questions are related to the preceding twelve months, it is possible that consequently the effect of ethical culture on unethical behaviour is not observed within the same period and that the improved behaviour is observed in the next measurement period. The collected data did not lend itself to testing this explanation. 


\section{Publications in the ERIM Report Series Research* in Management}

\section{ERIM Research Program: "Organizing for Performance"}

2009

On the Specification of the Gravity Model of Trade: Zeros, Excess Zeros and Zero-Inflated Estimation Martijn J. Burger, Frank G. van Oort, and Gert-Jan M. Linders ERS-2009-003-ORG

http://hdl.handle.net/1765/14614

The Current State of Research on Networks in China's Business System Johannes Meuer and Barbara Krug

ERS-2009-007-ORG

http://hdl.handle.net/1765/14842

Encountered Problems and Outcome Status in Nascent Entrepreneurship

A. Marco van Gelderen, B. Pankaj Patel, and A. Roy Thurik

ERS-2009-008-ORG

http://hdl.handle.net/1765/14913

The Ethics of Organizations: A Longitudinal Study of the U.S. Working Population

Muel Kaptein

ERS-2009-018-ORG

http://hdl.handle.net/1765/15405

* A complete overview of the ERIM Report Series Research in Management: https://ep.eur.nl/handle/1765/1

ERIM Research Programs:

LIS Business Processes, Logistics and Information Systems

ORG Organizing for Performance

MKT Marketing

F\&A Finance and Accounting

STR Strategy and Entrepreneurship 